\title{
FORMAÇÃO DE PROFESSORES DE QUÍMICA: CONCEPÇÕES DE RACIONALIDADE EM ESTÁGIO CURRICULAR SUPERVISIONADO
}

\section{CHEMISTRY TEACHER EDUCATION: CONCEPTIONS OF RATIONALITY IN SUPERVISED CURRICULAR INTERNSHIP}

\author{
Andreia Florencio Eduardo de Deus ${ }^{1}$ \\ Noemi Sutil ${ }^{2}$
}

\begin{abstract}
Resumo: O Estágio Curricular Supervisionado envolve problematização e articulação entre teoria prática. Este perfil de formação está relacionada com a autonomia, posicionamento dialógico e crítico frente as questões sociais. Este delineamento se aproxima da Teoria do Agir Comunicativo (TAC) de Jürgen Habermas. Destaca-se concepção de formação de professores fundamentada nos pressupostos da TAC. Propõe-se analisar concepções de racionalidade no contexto de Estágio Curricular de licenciandos em Química de uma instituição de Ensino Superior. A pesquisa do tipo exploratória agrega princípios qualitativos e envolve observação direta em atividades relacionadas ao Estágio Curricular. Os dados foram analisados conforme pressupostos da Análise de Conteúdo. Como resultado, observou-se a predominância da racionalidade instrumental no ideário dos licenciandos, a carência argumentativa e a ausência de participação efetiva do supervisor da escola no processo de formação. Entretanto, aponta-se para possíveis rupturas e o desenvolvimento de racionalidade comunicativa.
\end{abstract}

Palavras-chave: Formação de professores de Química; Estágio Curricular Supervisionado; Racionalidade Comunicativa.

\begin{abstract}
The Supervised Curricular Internship involves problematization and articulation between theory and practice. This training profile is related to autonomy, dialogical and critical positioning in relation to social issues. This outline approaches Jürgen Habermas' Theory of Communicative Action (TAC). We highlight the conception of teacher education based on the assumptions of the TAC. It is proposed to analyze conceptions of rationality in the context of Curricular Internship of graduates in Chemistry of an institution of Higher Education. Exploratory research adds qualitative principles and involves direct observation in activities related to the Curricular Stage. The data were analyzed according to the assumptions of Content Analysis. As a result, we observed the predominance of instrumental rationality in students' ideals, the lack of argument and the lack of effective participation of the school supervisor in the training process. However, it points to possible ruptures with the development of communicative rationality.
\end{abstract}

Keywords: Chemistry Teachers' Education; Supervised Curricular Internship; Communicative Rationality.

\footnotetext{
${ }^{1}$ Mestra em Educação em Ciências e em Matemática pela Universidade Federal do Paraná (UFPR). Pedagoga da Universidade Federal da Fronteira Sul (UFFS), Campus Realeza, Realeza, Paraná, Brasil. Email: andreiaflorencio98@gmail.com

${ }^{2}$ Doutora em Educação Para a Ciência pela Universidade Estadual Paulista Júlio de Mesquita Filho (UNESP). Professora adjunta da Universidade Tecnológica Federal do Paraná (UTFPR), Curitiba, Paraná, Brasil. E-mail: noemisutil@ hotmail.com
} 


\section{Introdução}

Tratar de questões relacionadas à formação inicial de professores requer uma compreensão mais ampla de aspectos subjetivos do ser humano e da complexidade do "ser professor" no contexto social. Demanda uma concepção de racionalidade que extrapole a perspectiva instrumental em processos formativos, que não se restringem aos cursos de formação inicial. Contudo, no âmbito desses processos formativos, os objetivos, conteúdos e atividades educacionais ainda agregam essa redução à racionalidade técnica, instrumental.

Nesse contexto, destacamos neste trabalho considerações concernentes às ações envolvendo o Estágio Curricular Supervisionado de um curso de Licenciatura em Química, envolvendo instâncias e sujeitos diversos, em relação Universidade-EscolaComunidade. Nessas ações e interações, destacamos a perspectiva de racionalidade comunicativa no desenvolvimento destes processos.

Nos espaços do Estágio Curricular Supervisionado, o licenciando traz consigo um acúmulo de conhecimentos e vivências desenvolvidos no âmbito do curso e em sua trajetória acadêmica e de vida. Durante o Estágio Curricular Supervisionado são agregadas à formação do licenciando compreensões e experiências do seu lócus profissional que podem confirmar ou redimensionar suas pretensões. Nesse sentido, Tardif e Lesard (2014, p. 51) apontam para a experiência considerando a "intensidade e a significação de uma situação vivida por um indivíduo", em referência às vivências que podem determinar a permanência do licenciando na profissão ou o seu rompimento.

Considerando a subjetividade da formação humana e seus meandros, considerando o processo formativo inicial de professores, neste trabalho, objetivou-se analisar concepções de racionalidade no contexto de Estágio Curricular Supervisionado de licenciandos em Química de uma instituição de Ensino Superior localizada na região sudoeste do estado do Paraná.

\section{Concepções de racionalidade}

Ao abordarmos a formação de homens e mulheres, situa-se a sua definição como ser racional, característica que os distingue dos outros animais. Porém, na tentativa de conceituar razão, interpõem-se alguns questionamentos.

Essa atribuição de conceituação de razão e racionalidade remete à filosofia. Nessa direção, Japiassu (2006, p. 30) apresenta a definição de racionalidade como "a 
adequação estabelecida entre a coerência lógica (descritiva ou explicativa) e determinada realidade empírica". No domínio do senso comum, pode-se situar a definição de razão associada a estado do ser humano em que este toma decisões em sua vida e na de outras pessoas com base em fatos e ações, sem agregar aspectos subjetivos.

Dentre os mais conhecidos filósofos que se debruçaram sobre a temática, o francês René Descartes defendeu a razão enquanto método lógico para se evitar o erro. A razão para este filósofo é essencialmente objetiva e por meio dela se obtém o conhecimento (GELAMO, 2007).

Para Immanuel Kant a razão é algo que pode conceder ao homem a sua liberdade. Este filósofo encontra problemas ao tratar de liberdade na sociedade de sua época e, nesse contexto, destaca o uso público e o uso privado da razão.

\begin{abstract}
Entendo, contudo sob o nome de uso público de sua própria razão aquele que qualquer homem, enquanto sábio, faz dela diante do grande público do mundo letrado. Denomino uso privado aquele que o sábio pode fazer de sua razão em certo cargo público, ou função a ela confiado (KANT, 2011, p. 66 grifo do autor).
\end{abstract}

Max Horkheimer, filósofo da Escola de Frankfurt, tece críticas à razão associada a fins previamente estabelecidos, razão objetiva. Em oposição afirma que a razão é também subjetiva. Contudo, em relação às proposições de Max Webber sobre a razão, Sell (2012, p. 157) expressa que “a visão weberiana de racionalidade se reduz, em última instância, apenas à racionalidade prática”.

Jürgen Habermas, filósofo com associações com a Escola de Frankfurt, concebe a razão e a racionalidade associando a linguagem, ou seja, a argumentação e a disposição dos indivíduos para o diálogo. Tais conceitos estão relacionados na Teoria do Agir Comunicativo (TAC). Os autores que o antecederam conceberam a razão e a racionalidade em diferentes enfoques: objetiva, libertária, subjetiva, prática. Habermas (2012a; 2012b) compreende a razão também com bases na linguagem, razão comunicativa e racionalidade comunicativa.

Esses construtos teóricos de Habermas (2012a, 2012b) em torno da razão abordam explicitamente a crítica à razão instrumental. Para o autor é pela linguagem que a razão se constitui e promove a apresentação das pretensões de validade em um determinado espaço constituindo o uso comunicativo do saber momentâneo.

Nesse escopo, situam-se os domínios do mundo da vida e do sistema. O mundo da vida constitui o espaço da interação comunicativa cotidiana direcionada ao entendimento e ao acordo, em que a linguagem assume a coordenação das ações. O 
sistema, por outro lado, rege-se por racionalidade instrumental, com respeito a fins, em que a coordenação das ações agrega dinheiro e poder.

Na ideia de mundo da vida, Habermas mostra a racionalidade dos indivíduos mediada pela linguagem e comunicatividade. Esses elementos se constituem em instrumentos de construção racional dos sujeitos calcados na estruturação de três universos: objetivo, subjetivo e social (SILVA, 2001, p. 5).

Na expressão habermasiana, a racionalidade como representação da técnica tirou do homem a capacidade de reflexão sobre si mesmo e sobre sua realidade. $\mathrm{O}$ avanço da ciência enquanto solução de problemas ou o sistema de produção como centro das preocupações humanas são aspectos da racionalidade instrumental dominante na sociedade.

\begin{abstract}
Os "custos" sociopsicológicos de uma racionalização limitada ao que é cognitivo instrumental ("custos" exteriorizados pela sociedade que vem onerar os indivíduos) manifestam-se enquanto fenômenos sob formas diversas - seu espaço de ação vai desde as doenças psíquicas clínicas, passando por neuroses, ocorrências de vícios, distúrbios psicossomáticos, problemas motivacionais ou educacionais, até a conduta contestatória de contraculturas de inspiração estética, seitas religiosas e jovens e grupos cominais marginalizados (que incluem também o terrorismo anarquista) (HABERMAS, 2012a, p. 635).
\end{abstract}

Na contramão dessa hegemonia, a racionalidade comunicativa proposta por Habermas (2012a, 2012b) tem a comunicação como promotora da interação humana nos mundos objetivo, social e subjetivo, no escopo do mundo da vida. $\mathrm{O}$ autor não descarta a importância social do sistema, mas argumenta a necessidade de interação deste com o mundo da vida que por sua vez só é possível pela comunicação.

Racionalidade comunicativa remete ao agir comunicativo, em que os sujeitos por meio de argumentação vislumbram o entendimento e o acordo, em formação de responsabilidade e autonomia. Esses processos demandam a comunicação livre de coerção, em que os participantes realizam atos de fala, que objetivam a tematização, a crítica e construção/reconstrução de aspectos no mundo objetivo, social e subjetivo.

O mundo objetivo se reporta à relação com a natureza externa e agrega os conhecimentos estabilizados, os saberes e as concepções. $\mathrm{O}$ mundo social se refere às atividades interativas e a premência de estabelecimento de normativas. O mundo subjetivo remete ao sujeito, suas percepções, seus aspectos idiossincráticos. Racionalidade comunicativa envolve a articulação entre esses mundos.

Em perspectiva da racionalidade instrumental, adquire destaque a manipulação técnica e aspectos de eficiência e eficácia. Agrega a divisão do trabalho, em que aspectos éticos e morais são preteridos. 
A preponderância da racionalidade instrumental em direcionamento a ações eficientes se relaciona à invasão sistêmica no mundo da vida. Nessa situação, a linguagem deixa de assumir a coordenação das ações, cedendo lugar a meios como dinheiro e poder. Nesse escopo, Habermas (2012a, 2012b) situa os aspectos de burocratização e jurisdização, com recursos a processos e normas preestabelecidas, sem a necessidade de questionamento de fins e meios. Entre as patologias envolvidas nessa colonização sistêmica, destaca-se a cultura de especialistas, aos quais se atribui a responsabilidade pelas decisões que afetam a sociedade, ampliando a divisão de trabalho e instaurando a falta de responsabilidade e autonomia.

\section{Formação de professores}

As décadas de 70 e 80 do século passado foram marcadas na história da educação brasileira, entre outros aspectos, pelos debates em torno da formação de professores, do caráter “instrumental técnico ao político da prática pedagógica” (DINIZPEREIRA, 2006, p. 18). As discussões em torno da formação de professores transcenderam os muros das instituições escolares, destacando aspectos culturais, sociais e subjetivos mais amplos.

Persistem, ainda, discussões e questionamentos nessa direção. A Universidade forma o professor para atuar em instituições escolares e, consequentemente, na sociedade? Ou a sociedade determina a formação deste profissional?

Revistando a linha histórica da educação, destacam-se aspectos de controle social estabelecidos também na formação de professores. As várias concepções de professor evidenciam as mudanças na sociedade. Contreras (2002) ao debater a identidade docente aponta alguns "modelos de professores". O especialista técnico é o professor que por meio de conhecimentos técnicos e exatos identifica os problemas e apresenta soluções precisas. O professor reflexivo se refere a um profissional que na ação da prática é capaz de refletir sobre ela. O intelectual crítico se relaciona ao professor que reflete sobre a educação para além de sua sala de aula.

Para além das definições atribuídas a este profissional os dias atuais trazem novos desafios. As tecnologias e o mundo globalizado trazem à escola o novo aluno, aquele cujo acesso ao mundo é cada vez maior, porém com dificuldades de reflexões mais aprofundadas. Encontra-se neste meio um dos grandes desafios do professor do século XXI. 
Nessas condições, as ações de intelectual crítico podem ser associadas à racionalidade comunicativa. Nesse sentido, o docente se posiciona como sujeito de questionamento e de proposições sobre aspectos dos mundos objetivo, social e subjetivo, visando à articulação entre teoria e prática. A compreensão do docente como participante desses processos críticos e construtivos se contrapõe à cultura de especialistas, viabilizando sua inserção nas definições de fins e meios nas ações educativas.

O processo de formação inicial de professores envolve atores e instâncias que interagem em torno de um personagem: o licenciando. Entende-se como necessidade urgente a superação do modelo de racionalidade técnica, instrumental, nos processos formativos dos docentes, ainda persistente em cursos de licenciatura. Conforme Fernandes e Gonçalves (2016, p. 252), "não se pode afirmar que a racionalidade técnica não mais oriente a formação pedagógica à qual os docentes da educação superior são submetidos".

Contudo, os direcionamentos propostos pela LDB 9394/96 (BRASIL, 1996), nas Diretrizes para a Formação de Professores (BRASIL, 2002) e, mais recentemente, na Resolução 02/2015/CNE (BRASIL, 2015), trazem mudanças significativas no intuito de uma formação de professores que não privilegie somente a técnica, mas um conjunto de saberes sociais, filosóficos, epistemológicos e políticos, que propicie ao licenciando uma visão ampla da sociedade.

Ainda nessa direção, ao referir-se especificamente ao Estágio Curricular Supervisionado, Zabalza (2014, p. 236) afirma que "seja qual for a estrutura e os propósitos formativos do estágio, este tem sempre uma dimensão pessoal que ultrapassa amplamente os objetivos acadêmicos”. Ou seja, as interações subjetivas do aluno contribuem para suas ações e compreensão do processo formativo.

\section{Características gerais da pesquisa}

Este trabalho envolve pesquisa do tipo exploratória e se desenvolve em princípios de pesquisa qualitativa. Esse processo foi desenvolvido no primeiro semestre de 2017 e abarcou 11 acadêmicos e um professor orientador do Ensino Superior.Tratase de uma turma do curso de Licenciatura em Química. O curso em questão é ofertado em uma instituição de ensino superior com características muito específicas, cuja a maior delas é o seu público-alvo. Mais de $90 \%$ dos alunos são oriundos de escola 
pública, está localizada em um município com uma população de 16 mil habitantes. O curso de Licenciatura em Química objeto de estudo foi criado em 2013, os licenciandos estudados são remanescente do processo de migração, ou seja, na sua origem o curso superior ofertado era Licenciatura em Ciências Naturais: Química, Física e ciências Biológicas. Em 2013 com a criação dos cursos de Licenciatura em Física, Licenciaturaem Química e Licenciatura em Ciências Biológicas, o curso original é fechado.

O curso de Ciências Naturas, criado em 2010 na implantação da instituiçãoiniciou o seu processo de extinção em 2013, sendo finalizado como os últimos formandos em Ciências Naturais: Química, Física e ciências Biológicas no ano de 2015. Muitos dos licenciando que optaram por migrar para os novos cursos ainda não haviam finalizado a sua graduação até o encerramento deste trabalho. Dos onze alunos objetos desta pesquisa dois colaram grau de licenciados em Química em dezembro de 2017.

Os dados da pesquisa foram constituídos por meio de observação direta de oito aulas do Componente Curricular Estágio Curricular Supervisionado II de Curso de Licenciatura em Química de uma instituição de Ensino Superior pública, com gravações em áudio e registros em diário de campo. Foram ainda realizadas entrevistas com professor orientador e licenciandos. Foram entrevistados os licenciandos em dias e horários pré-agendados, e posteriormente entrevistou-se o professor orientador. $\mathrm{O}$ roteiro desenhado para as entrevistas foi o mesmo para ambos os atores. As questões norteadoras apontavam para as concepções e análise do período de Estágio Curricular Supervisionado vivenciado pelos entrevistados, suas experiências enquanto alunos e perspectivas quanto a formação de professores. As entrevistas foram realizadas na fasefinal do componente curricular momento em que os licenciando já haviam experienciado a docência.

Esses dados foram analisados conforme pressupostos e características de Análise de Conteúdo (BARDIN, 2001). Das aulas observadas, gravadas em áudio e transcritas posteriormente, das anotações do diário de campo bem como das transcrições das entrevistas foram elencadas categorias a posteriori que evidenciam a nosso ver concepções de racionalidade.

$\mathrm{Na}$ primeira etapa de cada conjunto de dados (transcrições das aulas, diário de campo e entrevistas) emergiram categorias associadas a concepção de racionalidade, cabe-se ressaltar que cada conjunto de dados é oriundo de um contexto específico do 
mesmo grupo. Como a dinâmica de sala de aula, as percepções pessoais do diário de campo e a proximidade e individualidade da entrevista.

$\mathrm{Na}$ segunda etapa, os três conjuntos de dados foram analisadossimultaneamente e deles emergiram categorias que chamamos de principais. Com base em talclassificação foram analisadas as concepções de racionalidades que permearam o estagio curricular supervisionado do curso em questão.

$\mathrm{Na}$ apresentação de exemplares de análise, os licenciandos são identificados pela letra L seguida de número (exemplo: L1) e o professor orientador pela letra P. Esse processo envolveu a análise de concepções de racionalidade e suas implicações para o Estágio Curricular Supervisionado e para a formação de professores de Química.

\section{Concepções de racionalidade em Estágio Curricular Supervisionado de Curso de}

\section{Licenciatura em Química}

No contexto do Estágio Curricular Supervisionado do referido curso, os licenciandos já percorreram (neste caso) nove semestres (esse número pode ser maior em casos de licenciandos com retenções associadas a reprovações em componentes curriculares). Dessa forma, podem ser percebidos os caminhos percorridos, as interações estabelecidas e possíveis rupturas e confirmações. Nessa direção, no processo de análise de dados, os discursos dos licenciandos na interação com o professor orientador foram categorizados considerando preceitos da racionalidade instrumental e da racionalidade comunicativa (HABERMAS, 2012a, 2012b).

\subsection{Concepção de racionalidade instrumental}

Em diversas expressões, os licenciandos demonstram a compreensão de hierarquia no processo de ensino e aprendizagem, em que o professor orientador é o detentor do conhecimento e das regras; ao licenciando cabe apenas seguir as regras. Em uma dessas situações, ao se referir ao planejamento dos licenciandos para a regência, o professor orientador relata que fez sugestões nos planos de aula dos mesmos e enviou por e-mail, porém, não obteve o retorno dos alunos quanto à aceitação ou questionamento das sugestões. Respondendo à questão, o licenciando L1 expressa: “eu fiz as alterações, mas achei que não precisava responder mais". A situação apontada pode representar a incompreensão dos licenciandos quanto ao seu processo formativo e a função do professor remetendo ao processo de divisão do trabalho. Tal observação 
pode ser considerada preocupante visto que existe a possibilidade de reprodução desse sistema no futuro espaço de trabalho. Estão presentes nessa situação indícios de racionalidade instrumental (HABERMAS, 2012a, 2012b).

No contato com a instituição escolar, os licenciandos são capazes de identificar situações com as quais discordam, porém, não conseguem avançar no sentido de questionamento e exposições de opiniões e sugestões. Percebe-se novamente o entendimento de instâncias inquestionáveis. $\mathrm{Na}$ expressão "nós achamos errado, mas não conversamos com a escola", os licenciandos L1 e L5 descrevem seus posicionamentos ao identificar condições de ensino em relação a um aluno com deficiência que consideravam equivocadas. A situação aponta um conformismo com a realidade vivida sem maiores perspectivas e apontam para dois aspectos de racionalidade instrumental identificada por Habermas (2012a), a manipulação técnica e o processo de indução. Neste contexto quando o professor aponta o que deve ser trabalhado e as metodologias que devem ser usadas em sala pelos licenciandos, sem recursos de discussão e elaboração conjunta, são as suas percepções e entendimentos que estarão presentes na aula ministrada pelo licenciando o que pode configurar-se como manipulação técnica. Quando situações percebidas na sala de aula não são pautadas em espaços de articulação de saberes, demostram posicionamentos que podem ser compreendidos como processão de indução, ou seja, conduz o licenciando há pareceres pré estabelecidos.

As expressões dos licenciandos denunciam que a racionalidade instrumental ainda perpassa a formação de professores, assim como a predominância do sistema em relação ao mundo vida. Não distante disso a desvalorização cada vez maior da profissão torna a situação ainda pior, em que se destacam expressões de licenciandos que explicitaram não desejarem serem professores. L1: “eu gosto de dar aula, mas eu não quero ser professor não, agora tenho outros planos".

No Quadro 1 foram elencadas quatro categorias que denotam a preponderância da racionalidade instrumental associada à invasão sistêmica no mundo da vida, assim como exemplares de expressões dos licenciandos relacionadas.

\begin{tabular}{|c|c|}
\hline Categorias elencadas & Exemplares de expressões \\
\hline $\begin{array}{c}\text { Soberania da expressão/ação do professor } \\
\text { orientador }\end{array}$ & $\begin{array}{l}\text { L7: Daquela aula que nós mandamos o professor deu as } \\
\text { contribuições e nós fizemos, nem mandamos dizer se } \\
\text { concordávamos. } \\
\text { L8: Ah! Por que ainda é assim, não se costuma questionar } \\
\text { o professor. }\end{array}$ \\
\hline Soberania do sistema educacional & L3: tem o Núcleo que sempre tá em cima, tem que \\
\hline
\end{tabular}




\begin{tabular}{|c|l|}
\hline & cumprir isso e aquilo. \\
\hline $\begin{array}{c}\text { Concepção de profissional pronto e } \\
\text { acabado }\end{array}$ & $\begin{array}{l}\text { L8: Aquela incerteza que eu te falei de chegar o aluno } \\
\text { perguntar a gente não saber! }\end{array}$ \\
\hline Divisão entre teoria e prática & L6: as teorias são fáceis, mas a prática é difícil. \\
\hline
\end{tabular}

Quadro 1: Dimensões relacionadas à racionalidade instrumental

Fonte: Autores

A quase exclusividade da racionalidade instrumental no processo de formação de professores representa um descompasso com o que se espera do cidadão e da sociedade moderna. É um caminho que distância o professor da sua própria autonomia de pensar e agir e o torna prisioneiro do seu mundo particular em uma factível predominância do sistema e anulação do mundo da vida. Nas falas dos alunos é perceptível a impossibilidade de enfrentamento da condição estabelecida tanto no desenvolvimento do Estágio Curricular Supervisionado, quanto nas estruturas subjetivas do espaço escolar. O licenciando acaba por reproduzir as ações e falas adequando-se ao sistema.

Salienta-se, contudo, que Habermas (2012a, 2012b) não abdica do sistema, mas defende uma coexistência desses dois domínios. Ao analisar o trabalho do professor em sala de aula, Tardif e Lessard (2014, p. 280) argumentam que "a dimensão interativa da docência precisa ser relacionada também à sua dimensão instrumental, finalizada. $\mathrm{O}$ professor não apenas interage com os alunos, mas também busca com eles atingir fins e visa alguns resultados". Portanto, os questionamentos em torno da razão instrumental ocorrem não pela sua existência, mas sim pela sua predominância e as consequências advindas dessas ações.

\subsection{Concepção de racionalidade comunicativa}

Apesar da evidência de aspectos da racionalidade instrumental nas expressões dos licenciandos foram identificadas situações que demonstram o reconhecimento dos mesmos quanto à concepção de racionalidade comunicativa. Em situações em que os alunos identificaram ações e possibilidade de trabalho coletivo na escola, compreendese que este conceito com base na racionalidade comunicativa já está estabelecido. A ideia de que o trabalho conjunto dos professores na escola pode alcançar objetivos comuns e maiores apontada pelos alunos nas aulas do componente curricular, demostra rupturas com o tecnicismo e o isolamento social. Da mesma forma, a identificação de trabalho coletivo no dia a dia da escola evidencia também indícios de racionalidade comunicativa. 
Por outro lado, ainda há uma carência formativa no que diz respeito ao enfrentamento com vistas à quebra de paradigmas, quando o licenciando L1 expressa: "não adianta também a gente querer chegar na escola e apresentar essa proposta de coletividade. Eu tentei falar com vários professores para gente tentar fazer uma coletividade, mas ninguém queria". Ou seja, mesmo estabelecido o conceito de trabalho coletivo os licenciando ainda carecem de capacidadeargumentativa na defesa de uma postura de coletividade no ambiente escolar.

Outro exemplo disso é quando os alunos em muitos casos reproduzindo as expressões dos professores supervisores da escola encontram no sistema educacional brasileiro uma barreira intransponível para propor mudanças na escola ou na sala de aula, em aceitação e reprodução do que está estabelecido, "quando eu passei pela escola não tinha isso" (A3). A expressão usada pelo licenciando expressa uma memória não tão distante por se tratar de pessoas ainda muito jovens, que por um lado reproduz também situações vivenciadas enquanto aluno da escola básica e por outro indica o reconhecimento de mudança ocorrida naquele espaço temporal da sua passagem pela escola como aluno e o retorno como licenciando.

Neste escopo de análise apresentam-se situações opostas de reprodução de concepção de racionalidade instrumental e de reconhecimento de concepção de racionalidade comunicativa. O que emerge desta condição se encontra na característica do jovem, a inconstância e a fase de elaboração de conceitos.

\section{Considerações finais}

A formação de professores tem passado por inúmeras mudanças que acompanham a sociedade. Nesse contexto, não cabe mais o professor isolado do mundo, ou seja, não é possível insistir na formação de técnicos especialistas que não sejam capazes de interagir com o meio em que estão inseridos. As propostas de formação docente estabelecidas pelas novas diretrizes para a formação de professores representam avanços. Porém, o caminho ainda é longo.

$\mathrm{Na}$ pesquisa desenvolvida foram identificados indícios contundentes de concepções de professores como técnicos especialistas. Nessa situação, emergiram elementos que remetem aos conceitos de construções conjuntas e trabalho coletivo, de interação intersubjetiva, porém, há grandes dificuldades no que se refere à argumentação e posicionamento. Aponta-se que se trata de sujeitos que reconhecem 
aspectos de racionalidade comunicativa, todavia não se percebem como agentes de enfrentamentos e mudanças.

A racionalidade comunicativa defendida por Habermas (2012a; 2012b) remete a ações que privilegiem o trabalho coletivo com o objetivo do bem comum, em uma compreensão das instituições escolares como espaços de emancipação humana e consequente transformação social.

Entretanto, para que haja uma relação entre as instituições formadoras (Escola e Universidade), pautada no trabalho coletivo, com objetivo de formar os licenciandos nessa perspectiva emancipatória, é preciso rever outras questões, como, por exemplo, a formação dos formadores de professores.

\section{Referências}

BRASIL. Lei 9394, de 20 de dezembro de 1996. Estabelece as diretrizes e bases da educação nacional. Diário Oficial da União, Brasília, DF, 22 dez. 1996. Disponível em: <http://www.planalto.gov.br/Ccivil_03/leis/L9394.htm>. Acesso em: 27 fev. 2018.

BRASIL. Conselho Nacional de Educação. Resolução CNE/CP n. 01/2002, de 18 de fevereiro de 2002.Institui Diretrizes Curriculares Nacionais para a Formação de Professores da Educação Básica, em nível superior, curso de licenciatura, de graduação plena. Diário Oficial da União, Brasília, DF, 09 abr. 2002. Disponível em:

<http://portal.mec.gov.br/cne/arquivos/pdf/rcp01_02.pdf>. Acesso em: 27 fev. 2018.

BRASIL. Conselho Nacional de Educação. Resolução CNE/CP n. 02/2015, de $1^{\circ}$ de julho de 2015. Define as Diretrizes Curriculares Nacionais para a formação inicial em nível superior (cursos de licenciatura, cursos de formação pedagógica para graduados e cursos de segunda licenciatura) e para a formação continuada. Brasília, Diário Oficial da União, Brasília, DF, seção 1, n. 124, p. 8-12, 02 jul. 2015. Disponível em:

<http://pesquisa.in.gov.br/imprensa/jsp/visualiza/index.jsp>. Acesso em: 27 fev. 2018.

BARDIN, L. Análise de conteúdo. São Paulo: Edições 70, 2011.

CONTRERAS, J. A autonomia de professores. São Paulo: Cortez, 2002.

DINIZ-PEREIRA, J. E. Formação de professores: pesquisa, representações e poder. 2. ed. Belo Horizonte: Autêntica, 2006.

FERNANDES, C. S.; GONÇALVES, F. P. Reflexões epistemológicas acerca da racionalidade técnica na docência e no desenvolvimento profissional de formadores de professores de ciências da natureza. In: GÜLLICH, R. I.; HERMEL, E. E. S. (Org). Educação em ciências e matemática: Pesquisa e formação de professores. Chapecó: Editora UFFS, 2016. p. 251-266.

GELAMO, R. P. Filosofia do sujeito, pedagogia da razão e educação da infância e René Descartes. In: PAGNI, P. A.; SILVA, D. J. Introdução à filosofia da educação. Temas Contemporâneos e história. São Paulo: Avercamp, 2007. p. 126-145. 
HABERMAS, J. Teoria do Agir Comunicativo 1: Racionalidade da ação e racionalização social. São Paulo: Editora WMF Martins Fontes, 2012a.

HABERMAS, J. Teoria do Agir Comunicativo 2: Sobre a crítica da razão funcionalista. São Paulo: Editora WMF Martins Fontes, 2012b.

JAPIASSU, H. A crise da razão no ocidente. Pesquisa em Educação Ambiental, Ribeirão Preto, v. 1, n. 1, p. 27-41, 2006. Disponível em:

<http://www.revistas.usp.br/pea/article/view/30007/31894>. Acesso em: 27 fev. 2018.

KANT, I. Resposta à pergunta: Que é "esclarecimento"? (Aufklärung) In: KANT, I. Textos seletos. 7 ed. Petrópolis: Vozes, 2011. p. 63-71.

SELL, C. E. Racionalidade e racionalização em Max Weber. Revista Brasileira de Ciências Sociais, São Paulo, v. 27, n. 79, p. 153-172, 2012. Disponível em:

$<$ http://www.scielo.br/scielo.php script=sci_arttext\&pid=S0102-69092012000200010>. Acesso em: 27 fev. 2018.

SILVA, S. L. P. Razão instrumental e razão comunicativa: um ensaio sobre duas sociologias da racionalidade. Cadernos de Pesquisa Interdisciplinar em Ciências Humanas, Florianópolis, v. 2, n. 18, p. 2-9, jan. 2001. Disponível em:

<https://periodicos.ufsc.br/index.php/cadernosdepesquisa/article/view/944>. Acesso em: 27 fev. 2018.

TARDIF, M; LESSARD, C. O trabalho docente: elementos para uma teoria da docência como profissão de interações humanas. 9. ed. Petrópolis, Vozes, 2014.

ZABALZA, M. A. O estágio e as práticas em contextos profissionais na formação

universitária. 1. ed. São Paulo: Cortez, 2014.

Recebido em: 01 de agosto de 2018.

Aceito em: 12 de setembro de 2018. 